\title{
Effects of Early Training and Nicotine Treatment on the Performance of Male NMRI Mice in the Water Maze
}

\author{
Paloma Vicens, ${ }^{1}$ M. Carmen Carrasco ${ }^{2}$ and Rosa Redolat ${ }^{2}$ \\ 'Departament de Psicologia, Facultat de Ciències de l'Educació i Psicologia, Universitat Rovira i Virgili, \\ Carretera de Valls s/n. Tarragona 43007, SPAIN; ${ }^{2}$ Área de Psicobiología, Facultad de Psicologia, \\ Universitat de València, Avda Blasco Ibáñez, 21, Valencia 46010, SPAIN
}

\begin{abstract}
This research aimed to evaluate the effect of nicotine treatment and prior training on a spatial learning task in differently aged NMRI male mice. In a longitudinal study, mice were randomly assigned to one of 14 experimental groups receiving different combinations of chronically injected nicotine $(0.35 \mathrm{mg} / \mathrm{kg})$ administered for 10 days (5 days before and during 5 days acquisition of task) or control treatments and training in the water maze at different ages. The mice displayed shorter escape latencies when evaluated at 6 and 10 months than when tested in this task at 2 months for the first time, demonstrating that early training preserves performance in the water maze up to 8 months after the initial experience. Nicotine treatment did not significantly change performance in the water maze at any age tested. Early practice in a spatial reference memory task appears to have lasting consequences and can potentially contribute to preventing some age-related spatial learning deficits.
\end{abstract}

Reprint requests to: Dra. R. Redolat, Área de Psico-iología, Facultad de Psicologia, Universitat de València, Avda Blasco Ibáñez, 21, Valencia 46010, SPAIN. e-mail: rosa.redolat@uv.es

\section{KEYWORDS}

male NMRI mice, nicotine, early practice, spatial learning, reference memory

\section{INTRODUCTION}

Spatial cognition is essential for the integration of environmental information but progressively declines with advancing age in humans, monkeys and rodents (Erickson \& Barnes, 2003). Certain performance deficits in spatial task ability are observed at a relatively early age in rodents (Foster et al., 1996; Miyagawa et al., 1998). The need to pay attention to early manifestations of brain aging has been underscored both in humans and in ents (Finch, 2003). The Morris water maze task is a useful paradigm to investigate age-related spatial impairments since it is based on processes that may resemble human spatial functioning (Barnes, 1998; D'Hooge \& De Deyn, 2001), although individual differences among aged rats have been described in this paradigm (Gallagher et al., 2003). This animal model has been used to show a deficit of performance at 9 and 10 months of age in strains NMRI and C57 mice respectively (Magnuson, 1997). It is also reported that prior experience in spatial tasks can influence performance when animals are re-tested on the 
same task. Consequently, life-long experience can reduce the performance deficits in spatial memory tasks typically observed in aged rats (Dellu et al., 1997) and mice (Vicens et al., 2002). In a longitudinal study, Markowska and Savonenko (2002) found that repeated exposure to the task counteracted age-related deficits in a reference memory task in the water maze in rats.

Given the effects of spatial training in rodents, it was thought that a study of the interaction between drug effects and prior experience in the spatial task would be of considerable interest. The effects of certain drugs could well vary as a consequence of prior experience in the task. For example, a manipulation of muscarinic (Whishaw, 1989), NMDA, or benzodiazepine receptors (Keith \& Galizio, 1997) impairs the acquisition of the water maze task by naive rats but not by expert animals receiving non-spatial training. Diazepam impairs place learning in experimentally naive rats but does not alter learning in rats made familiar with the experimental conditions (Zanotti et al., 1994). Moreover, non-spatial pre-training in the water maze or pre-training in a different water maze alleviates or even almost completely prevents the learning deficit caused by an NMDA receptor antagonist in rats (Bannerman et al., 1995; Saucier \& Cain, 1995).

Nicotine is a substance extensively consumed by humans during adulthood, although there are suggestions that some of its behavioral actions may be sensitive to the age at which its use is initiated (Faraday et al., 2003; Levin \& Simon, 1998). A recent review of neurotransmitter systems involved in learning and memory of the water maze tasks indicates that acetylcholine is one of the more clearly implicated neurotransmitters, although the results obtained with the administration of cholinergic agonists and antagonists are complex (Myher, 2003). The nicotinic cholinergic system contributes to spatial processing (Cain, 1998; Sarter \& Bruno, 1998; Mc
Gehee, 2002), but the effects of nicotine on spatial reference memory are not very clear.

A variety of experiments performed using the water maze have shown that nicotine improves spatial reference memory in aged (Riekkinen et al., 1996; Riekkinen \& Riekkinen, 1997; Socci et al., 1995) and young rats (Abdulla et al., 1993; 1996; Hodges et al., 1995), whereas other studies using mice have either not replicated this finding (Lamberty \& Gower, 1991) or even reported an impairment (Bernal et al., 1999). Such divergent results are congruent with the effects of nicotine on spatial reference memory evaluated using the radial maze, since this drug did not improve performance of young rats (Levin, 1996). In a similar task, the administration of a nicotinic antagonist did not have significant effects on reference memory (Addy et al., 2003).

Apparently, no study has used nicotine to compare drug-induced performance in the water maze in mice tested at different ages and with varying familiarity with the task. It has been suggested that the age at which animals started testing in the water maze and the number of retesting periods could influence the effects of past practice on the performance of this spatial task (Markowska \& Savonenko, 2002). Experience in this spatial task could also be a strategy that modifies the behavioral effects of nicotine. In fact, certain authors have indicated that the effects of different drugs on performance in the water maze change, depending on their previous practice in the experimental task (Keith \& Galizio, 1997; Zanotti et al., 1994). For this reason, the main aim proposed in our research was to evaluate the potential influence of different combinations of nicotine administration on the acquisition and retrieval of memory related to the water maze task using a complex longitudinal design to compare performance in naive male NMRI mice and in those receiving training in the same task across their life-span. 
TABLE 1

Experimental design of the longitudinal study showing the treatment schedule in each experimental phase

\begin{tabular}{cccc}
\hline GROUPS & $\begin{array}{c}\text { TRAINING } \\
(\mathbf{2} \text { months })\end{array}$ & $\begin{array}{c}\text { TEST } \\
(\mathbf{6} \text { months })\end{array}$ & $\begin{array}{c}\text { RE-TEST } \\
(\mathbf{1 0} \text { months })\end{array}$ \\
\hline SAL-SAL-SAL & Saline & Saline & Saline \\
NIC-NIC-NIC & Nicotine & Nicotine & Nicotine \\
NIC-SAL-SAL & Nicotine & Saline & Saline \\
SAL-NIC-NIC & Saline & Nicotine & Nicotine \\
SAL-SAL-NIC & Saline & Saline & Nicotine \\
NIC-NIC-SAL & Nicotine & Nicotine & Saline \\
SAL-NIC-SAL & Saline & Nicotine & Saline \\
NIC-SAL-SAL & Nicotine & Saline & Saline \\
SAL-Not-SAL & Saline & No manipulation & Saline \\
NIC-Not-NIC & Nicotine & No manipulation & Nicotine \\
NIC-Not-SAL & Nicotine & No manipulation & Saline \\
SAL-Not-NIC & Saline & No manipulation & Nicotine \\
Not-Not-SAL & No manipulation & No manipulation & Saline \\
Not-Not-NIC & No manipulation & No manipulation & Nicotine \\
\hline
\end{tabular}

\section{EXPERIMENTAL}

\section{Subjects}

One hundred and forty male NMRI mice from CRIFFA (Iffa Credo, Barcelona, Spain) weighing $32.96 \mathrm{~g}( \pm 2.8)$ on arrival at the laboratory were used as subjects. The animals were housed in groups of five and kept in a climate-controlled vivarium (temperature $20 \pm 2{ }^{\circ} \mathrm{C}$ ) on an artificial light/dark regime (lights off from 08:00 to 20:00 h local time). Mice were supplied with standardized food pellets (Panlab, Barcelona, Spain) and tap water ad libitum. Principles of laboratory animal care were followed according to national and international guidelines.

\section{Apparatus}

The mice were tested in a Morris water maze made of black Plexiglas $(1 \mathrm{~m}$ diameter and $30 \mathrm{~cm}$ high), based on that described by Morris (1984) but adapted for mice. The maze was filled with water to a depth of $15 \mathrm{~cm}$ and maintained at $24 \pm$ $1{ }^{\circ} \mathrm{C}$. A small transparent platform $(6 \times 6 \mathrm{~cm})$ submerged $1 \mathrm{~cm}$ below the surface of the water was located in the NW quadrant (target quadrant).

The mice performed 4 trials per day for 5 consecutive days and, at this time were allowed 60 $\mathrm{sec}$ to find the hidden platform. If unable to do so, the mice were led to it by the experimenter. When on the platform, regardless of whether it was found independently or after guidance, the animals were 
allowed to stay for $30 \mathrm{sec}$ and observe their surroundings. A $30 \mathrm{sec}$ inter-trial interval was given. Starting positions from the three possible sites on the perimeter of the pool, situated in each of the quadrants not occupied by the platform, were chosen at random as in previous studies (Moragrega et al., 2003; Vicens et al., 1999; 2002). The starting positions for each day were determined so that all animals started equally from each point; two successive trials never began from the same position. At the end of the fourth trial of the last day, a probe trial was given during which the platform was removed and mice were allowed to swim for $60 \mathrm{sec}$. This trial was recorded by a video-camera (Panasonic M7 VHS, Japan). The measures obtained were escape latency (time to reach the submerged platform) and search time in each quadrant during the probe trial.

\section{Drugs}

Mice received (-)-Nicotine di-(+) tartrate salt $(0.35 \mathrm{mg} / \mathrm{kg}$ as base) (SIGMA-Aldrich, Madrid, Spain) dissolved in isotonic saline $(0.9 \% \mathrm{NaCl})$ injected at a volume of $10 \mathrm{ml} / \mathrm{kg}(\mathrm{Nic})$, control injections of physiological saline (Sal) or no treatment (Not), according to the treatment schedule (see Table 1). The $\mathrm{pH}$ of the nicotine solution was adjusted to 7 by adding dilute $\mathrm{NaOH}$. Both nicotine and physiological saline were administered subcutaneously (SC) $15 \mathrm{~min}$ before the performance of the spatial task.

\section{Procedure}

Mice were assigned to one of 14 experimental groups and evaluated in the water maze at different ages: 2 months (Training Phase, $n=140$ ), 6 months (Test Phase, $\mathrm{n}=126)$ and 10 months (Retest Phase, $\mathrm{n}=110$ ) when appropriate in each group in accord with the treatment schedule (see Table 1). Along the longitudinal study, the loss of animals from natural death decreased the number of mice in some groups, especially during Re-test phase. The testing period (every 4 months) was selected because in an earlier longitudinal study in NMRI mice this period allowed the observation of changes in performance (Vicens et al., 1999).

Nicotine or physiological saline were administered five days before the beginning of the experimental task and during the five acquisition days. Each group also received a denomination composed of three abbreviations, indicating the phase (Training, Test, Retest) at which the drug and experience in the water maze was given (see Table 1).

Training phase ( 2 months): Half of the twelve groups trained in this phase were treated with nicotine and the other half received physiological saline (see Table 1). These groups were trained in the water maze at 2 months of age, receiving 4 trials for 5 consecutive days, as described in the 'Apparatus' section. Two groups to be tested at 10 months as 'naïve' mice did not receive training or pharmacological treatment at this phase.

Test phase (6 months): In this phase, in accord with the experimental protocol (see Table 1), mice were injected with nicotine or physiological saline and evaluated in the spatial task at 6 months of age in the same room and with exactly the same disposition of spatial cues as in the training test. Treatment administration is described in detail in Table 1.

Re-test phase (10 months): The performance of naive animals at 10 months of age were compared with groups of mice of the same age that had received previous training in the water maze at 2 months of age, and with other groups that had been trained at both 2 and 6 months of age. All groups previously trained in the task received pharmacological treatment (nicotine or physiological saline) according to the experimental design (see Table 1). In addition, one naive group (no drug administration or behavioral experience) 
was injected with nicotine (Not-Not-Nic Group) and another naive group received physiological saline injection (Not-Not-Sal Group) (see Table $1)$.

\section{Statistical analyses}

Differences between groups in task acquisition and in the probe trial were assessed by analysis of variance (ANOVA), taking into account the factor Treatment (indicating the different groups which received varied combinations of nicotine and behavioral training) as between-subject factor, and the factors Day and Trial as within-subject variables. Post hoc analyses were made with Newman-Keuls tests. To evaluate the differences between phases, we conducted an additional
ANOVA, taking into account the factor Treatment as between-subject factor and Phase, Day, and Trial as within-subject factors. In these analyses, only groups that were tested in the water maze in the two phases of each comparison were taken into consideration.

\section{RESULTS}

Water maze performance at each phase of the longitudinal study

Training Phase (2 months of age): An overall analysis of all groups receiving nicotine or saline in this phase indicated that drug treatment had no significant effect on escape latency. Additionally,

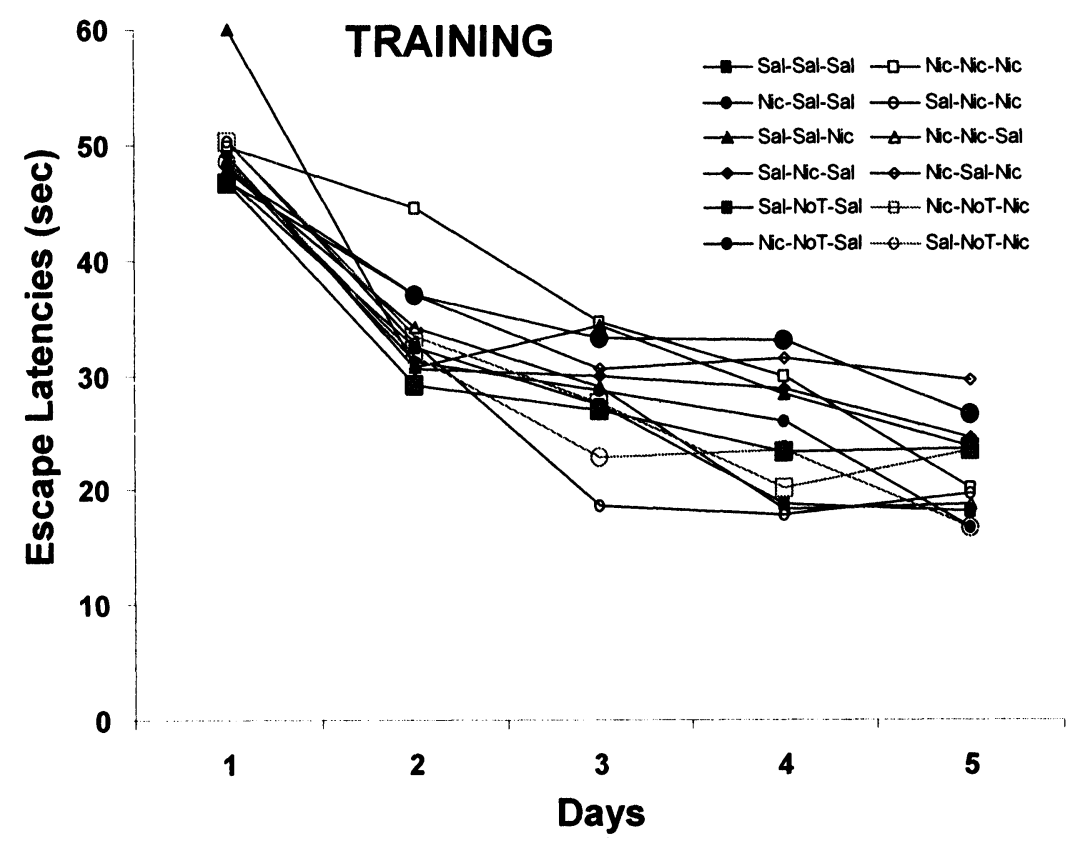

Fig. 1: Mean ( \pm SEM) daily escape latencies (averaged over four trials/day) of NMRI mice at 2 months of age (training phase). In this phase, mice assigned to 12 experimental groups were evaluated. Each group is named according to the drug treatment in each phase of the longitudinal study: nicotine (Nic), physiological saline ( $\mathrm{Sal}$ ) and no drug treatment or behavioral manipulation (Not). In this training phase, 6 groups received saline and 6 groups received nicotine, as indicated with the first abbreviation used for the legend of each group. 


\section{TABLE 2}

Mean Percentages Search Times in Quadrants during Probe Trial at two months of age (Training Phase)

\begin{tabular}{ccccc}
\hline Group & SE & NE & SW & NW \\
\hline Sal-Sal-Sal & $18.97 \pm 2.4$ & $20.65 \pm 2.3$ & $25.09 \pm 3.2$ & $35.58 \pm 2.5$ \\
Nic-Nic-Nic & $23.74 \pm 3.9$ & $16.79 \pm 2.6$ & $24.90 \pm 2.4$ & $32.76 \pm 3.0$ \\
Nic-Sal-Sal & $23.18 \pm 3.1$ & $20.18 \pm 3.0$ & $21.87 \pm 2.6$ & $35.33 \pm 5.4$ \\
Sal-Nic-Nic & $21.75 \pm 3.8$ & $13.60 \pm 1.8$ & $24.93 \pm 3.3$ & $39.60 \pm 4.1$ \\
Sal-Sal-Nic & $20.29 \pm 2.7$ & $17.81 \pm 2.5$ & $27.17 \pm 3.2$ & $29.74 \pm 4.1$ \\
Nic-Nic-Sal & $20.03 \pm 2.4$ & $21.17 \pm 1.1$ & $24.82 \pm 1.9$ & $33.50 \pm 3.5$ \\
Sal-Nic-Sal & $20.35 \pm 2.9$ & $20.45 \pm 3.1$ & $27.24 \pm 2.5$ & $32.06 \pm 3.6$ \\
Nic-Sal-Nic & $25.97 \pm 2.8$ & $22.29 \pm 2.4$ & $24.26 \pm 2.2$ & $27.45 \pm 3.3$ \\
Sal-Not-Sal & $18.76 \pm 1.7$ & $21.73 \pm 4.1$ & $19.44 \pm 1.9$ & $39.55 \pm 3.3$ \\
Nic-Not-Nic & $24.03 \pm 1.8$ & $20.65 \pm 2.3$ & $26.03 \pm 1.3$ & $28.90 \pm 3.0$ \\
Nic-Not-Sal & $23.32 \pm 2.7$ & $18.31 \pm 2.2$ & $28.29 \pm 3.5$ & $30.33 \pm 3.0$ \\
Sal-Not-Nic & $21.80 \pm 2.8$ & $17.08 \pm 2.9$ & $27.07 \pm 2.6$ & $34.32 \pm 4.3$ \\
\hline
\end{tabular}

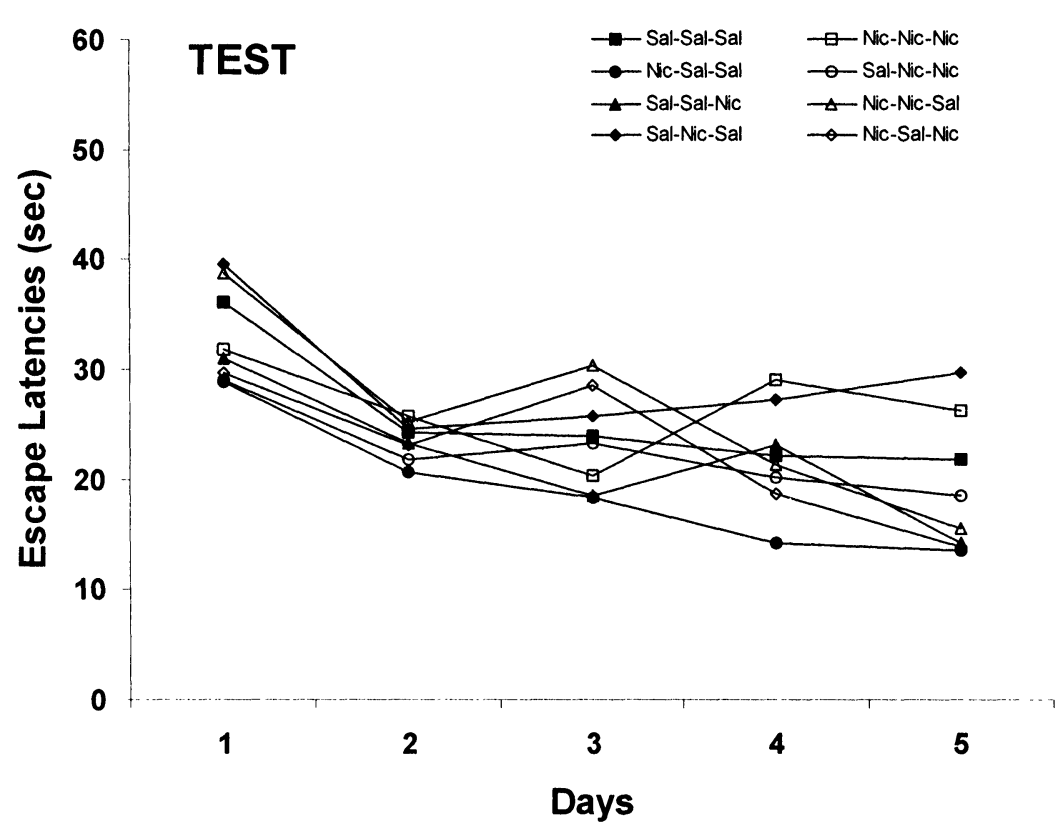

Fig. 2: Mean ( \pm SEM) daily escape latencies (averaged over four trials/day) of NMRI mice at 6 months of age (test phase). In this phase, mice assigned to 8 experimental groups were evaluated. Each group is named according to the drug treatment in each phase of the longitudinal study: nicotine ( $\mathrm{NiC}$ ), physiological saline ( $\mathrm{Sal}$ ) and no drug treatment or behavioral manipulation $(N o t)$. In this test phase, 4 groups received saline and 4 groups received nicotine, as indicated with the second abbreviation used for the legend of each group. 
TABLE 3

Mean Percentages Search Times in Quadrants during Probe Trial at six months of age (Test Phase)

\begin{tabular}{ccccc}
\hline Group & SE & NE & SW & NW \\
\hline Sal-Sal-Sal & $18.00 \pm 3.1$ & $17.44 \pm 3.1$ & $24.96 \pm 4.6$ & $34.72 \pm 6.1$ \\
Nic-Nic-Nic & $22.57 \pm 3.6$ & $12.50 \pm 2.1$ & $24.30 \pm 2.0$ & $36.30 \pm 4.3$ \\
Nic-Sal-Sal & $13.78 \pm 1.3$ & $10.48 \pm 2.5$ & $30.54 \pm 2.6$ & $41.41 \pm 3.2$ \\
Sal-Nic-Nic & $12.96 \pm 2.3$ & $14.00 \pm 4.0$ & $22.94 \pm 2.6$ & $45.98 \pm 7.2$ \\
Sal-Sal-Nic & $16.94 \pm 3.0$ & $16.15 \pm 2.8$ & $23.13 \pm 1.5$ & $42.31 \pm 5.3$ \\
Nic-Nic-Sal & $20.72 \pm 2.4$ & $14.04 \pm 2.6$ & $31.43 \pm 6.7$ & $33.87 \pm 4.7$ \\
Sal-Nic-Sal & $20.00 \pm 2.1$ & $18.50 \pm 2.7$ & $20.33 \pm 3.3$ & $36.90 \pm 5.0$ \\
Nic-Sal-Nic & $21.04 \pm 2.5$ & $26.96 \pm 7.7$ & $25.65 \pm 8.7$ & $28.42 \pm 5.6$ \\
\hline
\end{tabular}

the performance of groups receiving nicotine or saline before and during the acquisition of the water maze task was compared using ANOVA. The analysis indicated that the factor Treatment was not statistically significant. Mice learned to localize the platform faster over the course of days $(\mathrm{F}(4,468)=103.353 \mathrm{p}<0.0001)$, displaying longer escape latency on days 1 and 2 than on all the other days and longer on day 3 than on day 5 $(p<0.01)$ (see Fig. 1). The factor Trial was statistically significant $(\mathrm{F}(3,351)=7.086 \mathrm{p}<$ 0.01 ). Post hoc Newman-Keuls tests showed a better performance in trial 4 than in trials 1 and 2 $(\mathrm{p}<0.01)$, and in trial 3 than in trial $1(\mathrm{p}<0.05)$. No interaction between factors reached statistical significance.

The results of the probe trial are shown in Table 2. The factor Quadrant was statistically significant $\quad(F(3, \quad 360)=44.831, \quad p<0.0001)$ showing that mice spent more time in NW quadrant than in all the others $(p<0.01)$ and in SW quadrant more than in SE and NE quadrants ( $p$ $<0.05$ ). Moreover, mice swam longer in the SE quadrant than in NE $(p<0.05)$ (see Table 2). Treatment $x$ Quadrant interaction did not reach statistical significance. Additionally, an overall analysis combining all groups receiving nicotine or saline when this training phase was performed confirmed that there were no significant differences in time spent in the target quadrant $(\mathrm{NW})$ in mice undergoing either pharmacological treatment.

Test Phase ( 6 months of age): Groups with prior experience in the water maze at 2 months of age under saline or nicotine treatment and receiving the same or different pharmacological treatments in the test phase were compared (see Table 1). The ANOVA revealed no differences between groups receiving different treatments. The factor Day reached statistical significance (F (4, $256)=19.396 p<0.0001)$. Mice showed longer escape latencies on day 1 than on all other days $(p<0.01)$ (see Fig. 2). No other factor or interaction reached statistical significance.

Results of probe trial are shown in Table 3. ANOVA showed that the factor Quadrant was statistically significant $(\mathrm{F}(3,192)=37.63 \mathrm{p}<$ $0.0001)$. The animals spent more time in NW quadrant than in the rest $(p<0.01)$ and more in SW quadrant than in NE and SE $(p<0.01)$. The interaction Treatment $x$ Quadrant was not statistically significant. 
Re-test Phase (10 months of age): Groups with one or two experiences in the water maze under different drug manipulations (see Table 1) and which were subsequently given the same or a different drug treatment before being tested on the spatial task were compared. In addition, two control groups were tested for the first time at this age when given nicotine or saline injections. The ANOVA showed significant differences between groups $(F(13,96)=2.823 p<0.01)$, although post hoc Newman-Keuls test did not identify the source of any of these differences. Animals swam faster over days $(F(4,384)=30.991 p<0.0001)$ and showed a worse performance on day 1 than all the other days and on day 2 than on day $5(p<0.01)$ (see Fig. 3). Only the interaction Treatment $x$ Day $x$ Trial was statistically significant $(F(12,1248)=$
$2.039 \mathrm{p}<0.05)$

The factor Quadrant was also statistically significant $(F(3,288)=52.152 \mathrm{p}<0.0001)$ showing that mice spent more time in NW quadrant than in the rest $(p<0.01)$ and in SW quadrant than in SE and NE quadrants $(p<0.05)$ (see Table 4). Moreover, the interaction Treatment x Quadrant was statistically significant (F (39, $288)=1.728 p<0.0065)$. An ANOVA for each group was made to analyze this interaction showing that Sal-Sal-Sal, Nic-Sal-Sal, Sal-NicNic, Nic-Nic-Sal, Sal-Not-Sal and Sal-Not-Nic groups spent more time in NW quadrant than in the others $(p<0.05)$. Groups Nic-Nic-Nic and SalNic-Sal spent more time in NW than in SE and NE $(p<0.05)$ and the group Nic-Sal-Nic spent more time in NW than in NE $(p<0.05)$.

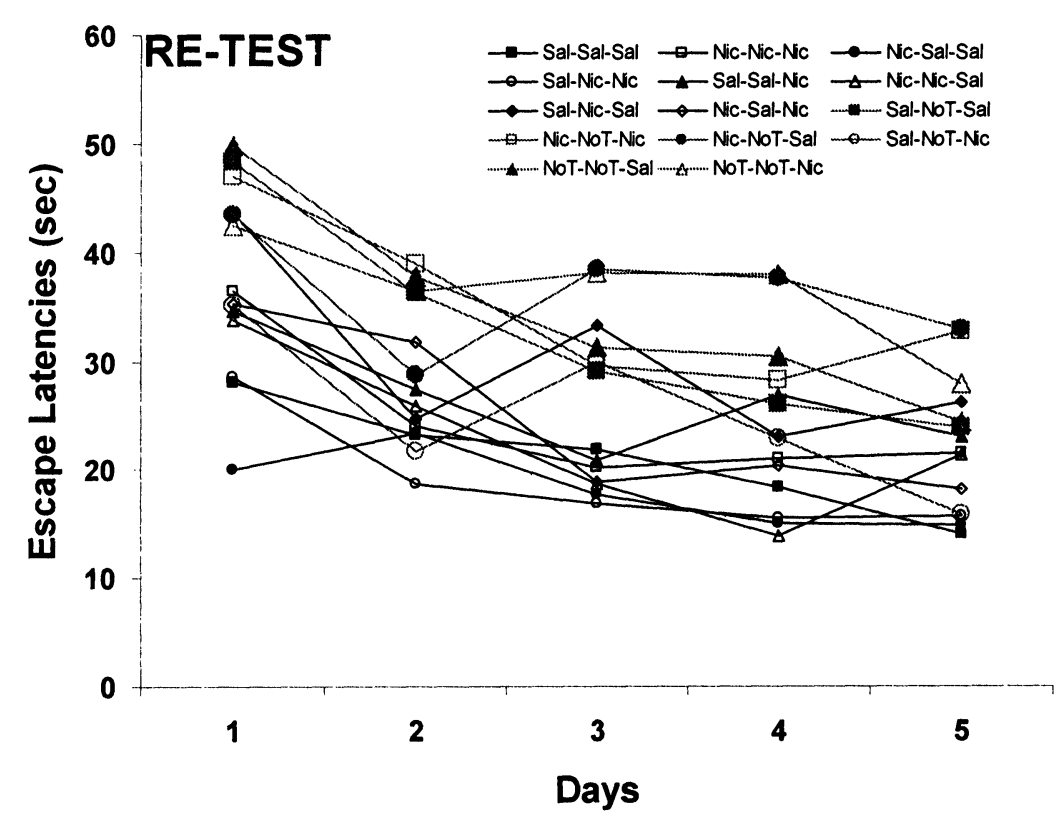

Fig. 3: Mean ( \pm SEM) daily escape latencies (averaged over four trials/day) of NMRI mice at 10 months of age (re test phase). In this phase, mice assigned to 14 experimental groups were evaluated. Each group is named according to the drug treatment in each phase of the longitudinal study: nicotine (Nic), physiological saline ( $\mathrm{Sal}$ ) and no drug treatment or behavioral manipulation (Not). In this re-test phase, 7 groups received saline and 7 groups received nicotine, as indicated with the third abbreviation used for the legend of each group. 
TABLE 4

Mean Percentages Search Times in Quadrants during Probe Trial at ten months of age (Re-test Phase)

\begin{tabular}{lcccc}
\hline \multicolumn{1}{c}{ Group } & SE & NE & SW & NW \\
\hline Sal-Sal-Sal & $18.70 \pm 2.7$ & $14.43 \pm 2.1$ & $25.67 \pm 5.1$ & $38.52 \pm 4.9^{*}$ \\
Nic-Nic-Nic & $17.52 \pm 2.9$ & $17.13 \pm 4.2$ & $25.67 \pm 4.0$ & $35.87 \pm 4.1^{+}$ \\
Nic-Sal-Sal & $18.98 \pm 2.7$ & $11.85 \pm 1.7$ & $25.23 \pm 2.0$ & $41.56 \pm 4.6^{*}$ \\
Sal-Nic-Nic & $16.46 \pm 4.5$ & $18.13 \pm 2.8$ & $17.00 \pm 3.1$ & $44.33 \pm 8.8^{*}$ \\
Sal-Sal-Nic & $23.88 \pm 2.4$ & $16.92 \pm 4.8$ & $23.13 \pm 2.5$ & $34.15 \pm 7.5$ \\
Nic-Nic-Sal & $22.41 \pm 3.3$ & $15.94 \pm 1.8$ & $20.41 \pm 2.2$ & $35.81 \pm 3.5^{*}$ \\
Sal-Nic-Sal & $17.77 \pm 3.6$ & $13.98 \pm 3.0$ & $25.21 \pm 3.0$ & $38.48 \pm 7.3^{+}$ \\
Nic-Sal-Nic & $21.50 \pm 3.2$ & $13.72 \pm 3.0$ & $26.94 \pm 4.8$ & $32.19 \pm 2.9^{\#}$ \\
Sal-NoT-Sal & $12.88 \pm 2.1$ & $19.77 \pm 4.2$ & $17.98 \pm 3.5$ & $45.46 \pm 4.6^{*}$ \\
Nic-NoT-Nic & $21.50 \pm 2.1$ & $18.79 \pm 4.2$ & $29.08 \pm 5.3$ & $23.81 \pm 3.6$ \\
Nic-NoT-Sal & $27.31 \pm 3.3$ & $23.96 \pm 5.4$ & $17.54 \pm 3.5$ & $26.19 \pm 5.1$ \\
Sal-NoT-Nic & $14.45 \pm 2.7$ & $9.71 \pm 3.2$ & $23.40 \pm 4.3$ & $48.17 \pm 5.8^{*}$ \\
NoT-NoT-Sal & $23.22 \pm 2.7$ & $19.96 \pm 3.1$ & $23.78 \pm 3.3$ & $28.15 \pm 4.4$ \\
NoT-NoT-Nic & $21.06 \pm 4.5$ & $17.85 \pm 2.3$ & $26.46 \pm 2.1$ & $28.67 \pm 4.9$ \\
\hline
\end{tabular}

${ }^{*} \mathrm{p}<0.05 \mathrm{NW}$ quadrant vs. all the other quadrants

$+p<0.05 \mathrm{NW}$ quadrant vs. SE and NE quadrants

\# $\mathrm{p}<0.05 \mathrm{NW}$ quadrant vs. NE quadrant

Water maze performance at different phases of the longitudinal study: Training, Test, and Re-test

Comparison between Training ( 2 months) and Test ( 6 months) phases: The factor Phase reached statistical significance $(F(1,52)=30.268 p<0.0001)$, showing a shorter escape latency in Test than in Training phase $(p<0.01)$ (Fig. 4). In addition, the mice learned to localize the hidden platform over days $(F(4,208)=62.524 p<0.0001)$. There was no interaction between factors Phase and Treatment.

Comparison between Training ( 2 months) and Re-test (10 months) phases: ANOVA showed differences in the factor Phase $(F(1,80)=19.363 p$ $<0.0001)$ indicating a better performance in the Retest than in the Training phase $(p<0.01)$ (see Fig. 4). The factor Day was also statistically significant $(\mathrm{F}(4,320)=112.687 \mathrm{p}<0.001)$, as was the interaction Treatment $x$ Phase $(F(11,80)=2.11 \mathrm{p}<$ 0.05).

Comparison between Test ( 6 months) and Retest (10 months) phases: Figure 4 shows that there were no significant differences between phases. The factor Day reached statistical significance ( $F(4$, $208)=35.531 \mathrm{p}<0.0001)$. No interaction was statistically significant. 

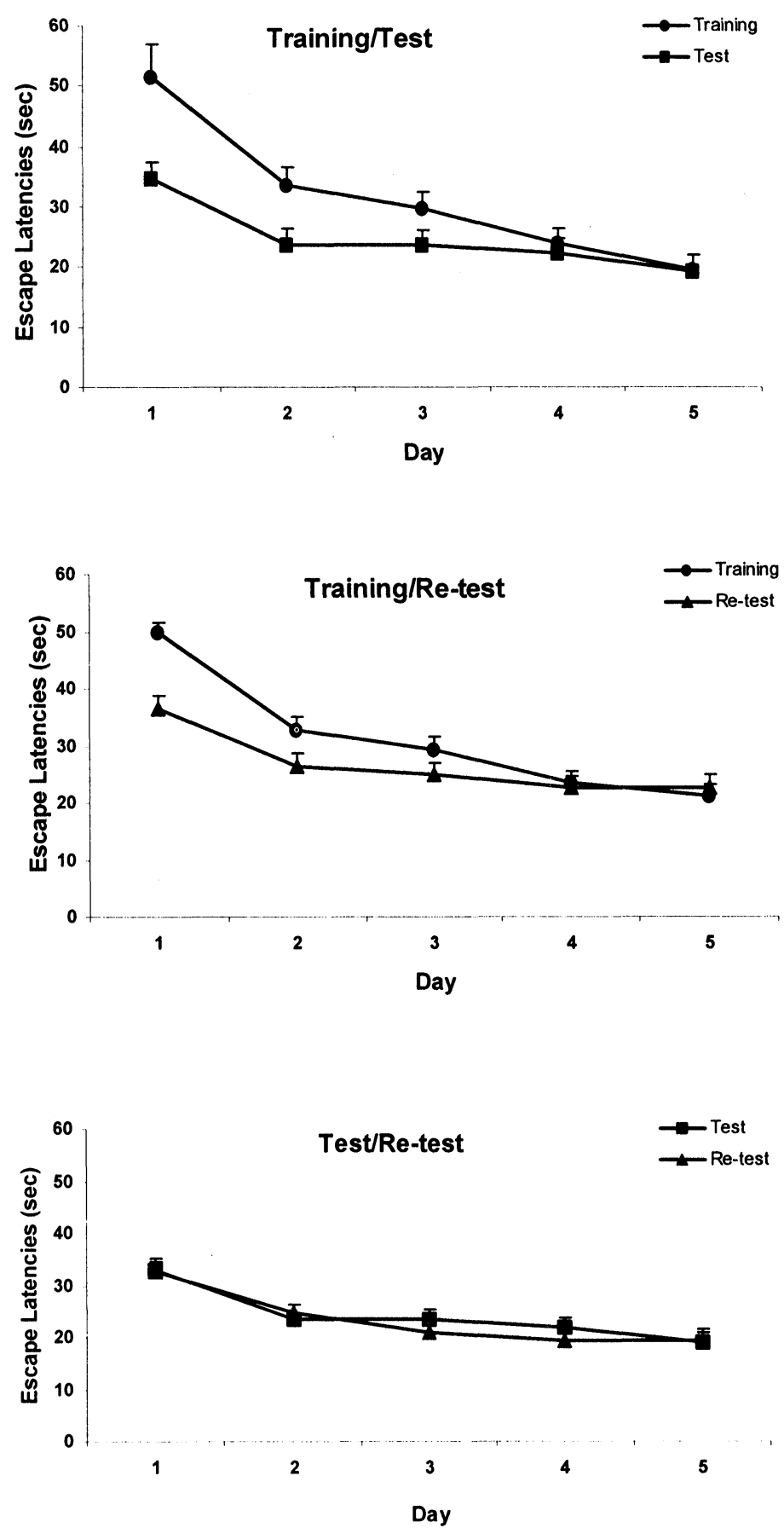

Fig. 4: Comparisons between the mean ( \pm SEM) daily escape latencies (averaged over four trials/day) of all groups tested at 2 months of age (training phase), 6 months of age (test phase) and 10 months of age (re-test phase). 


\section{DISCUSSION}

The present research aimed to evaluate whether the performance of a spatial learning task at different ages is influenced by a behavioral intervention (training in the water maze) and a pharmacological manipulation (chronic nicotine administration).

Effects of nicotine administration on watermaze performance at different ages: The findings presented here show that nicotine at the dose tested did not change the water maze performance of NMRI mice at any of the ages tested, reflecting that the age at which nicotine was administered did not influence spatial reference memory. At 10 months of age (re-test phase), a comparison between the performances of all groups (both with or without one or two previous experiences in the water maze task) indicates that chronic nicotine administration had no clear positive effect on NMRI mice at this age. In fact, 10 -month old naive mice receiving $0.35 \mathrm{mg} / \mathrm{kg}$ of nicotine did not show a better acquisition or retention of the water maze task than did the naive vehicle-treated mice. The results of this study agree with previous reports indicating no beneficial effect of nicotine administration on the acquisition or retention of spatial tasks (Bernal et al., 1999; Lamberty \& Gower, 1991), although in these studies the effects of age were not specifically tested. This issue is, however, important because some reports indicate a great variance in behavioral responses to nicotine administration in rodents of different ages. For example, adolescent male rats are more sensitive than adults to nicotine's activity-enhancing effects in the actimeter (Faraday et al., 2001; 2003). Also reported is that early adolescent mice (24 to 35 days old) have a greater vulnerability to nicotine, showing a marked stable preference for oral selfadministration (Adriani et al., 2002). Our data indicate that the age at which mice were tested in the present experiment did not modify the action of nicotine in the water maze task because no significant differences in performance occurred after pharmacological treatment.

Variability in mouse strain, drug dose, or treatment duration could account for the discrepancy between studies reporting divergent nicotine effects on spatial learning. For example, Lamberty and Gower (1991) failed to obtain significant effects of nicotine administration to antagonize the scopolamine-induced impairment of performance in the water maze in female NMRI mice. In $\mathrm{C} 57$ male mice, when nicotine was administered at a dose similar to that used in the present research, only during acquisition days, it did not improve performance in the water maze; and actual impairment was observed with a higher dose (Bernal et al., 1999). In this strain of mice, however, a beneficial effect of nicotine on acquisition of a spatial task after chronic treatment for 9 days was reported (Bernal et al., 1999).

The failure of nicotine to improve spatial learning may also be explained, in part, by the good spatial ability displayed by NMRI mice because this strain shows a rapid acquisition of the task (Vicens et al., 1999), although earlier findings had suggested that such mice display a spatial learning deficit at 9 months (Lamberty \& Gower, 1990). In the present experiment, naive mice tested at 10 months of age for the first time showed a worse retention of the platform location, although they had no acquisition deficit. Thus, it can be hypothesized that to observe any improvement in task performance induced by nicotine might be difficult because mice used in the current study did not show a clear spatial deficit.

Effects of spatial training and nicotine administration at different ages on water maze performance: The results presented here indicate that NMRI mice display shorter escape latencies when evaluated at 6 and 10 months than when tested in the water maze task at 2 months for the first time. This observation demonstrates that early 
training in this task could have a positive influence 8 months after the initial experience, even when mice did not receive an intermediate re-testing. Mice displayed better acquisition of the water maze task in re-test and test phases than in the training phase, although no significant differences between them were obtained. The data suggest beneficial effects of prior experience both in mice trained only at 2 months of age and those trained in the water maze at 2 and re-tested at 6 months of age. In interpreting these results, we can conclude that practice in this spatial task at an early age might prevent some of the aged-related spatial deficits that have been described in earlier reports.

The positive influence of previous experience was more evident during acquisition trials along daily sessions than in the probe trial. However, when mice were evaluated at 10 months of age, deterioration in the retention of the platform position, as reflected in the probe trial, was observed in animals tested for the first time at this age (Groups Not-Not-Nic and Not-Not-Sal). These findings indicate that early-life experience could be a critical tool to improve reference memory, suggesting that spatial cognitive decline associated with age would be ameliorated by means of this behavioral intervention. Therefore, the results presented here support those of other studies demonstrating that previous experience can preserve or even improve the performance of rodents in a spatial task, even after a long period without training (Dellu et al., 1997; Fordyce \& Wehner, 1993; Markowska \& Savonenko, 2002; Miyagawa et al., 1998; Moser et al., 1997; PerrotSinal et al., 1996; Pitsikas et al., 1991) and extend those of earlier reports indicating the beneficial influence of prior training at an early age in NMRI mice (Vicens et al., 1999; 2002). Such a protective effect of experience is consistent with studies in humans, which have demonstrated the efficacy of spatial training in age-related cognitive deficits
(Moffat et al., 2001).

Certain hypotheses have been postulated to explain beneficial effects of training in learning tasks. Age differences in spatial learning in rats have been related to rigidity in place cell firing patterns (Tanila et al., 1997). Recent evidence confirms a correlation between spatial memory evaluated in the water maze task and spatial representations in hippocampal cells, supporting a difference in information-processing ability between young and aged hippocampus (Wilson et al., 2003). It has been suggested that previous experience in the water maze could confer a protection from age-related deficits in spatial memory. In this preservation, training at an early age could be acting as a complex stimulation favoring brain plasticity mechanisms, inducing neurobiological changes similar to those described after environmental enrichment (Moser et al., 1997; Van Praag et al., 2000).

In addition, possibly past experience in the water maze could reduce the incidence of stress or anxiety-related behaviors that appear after the initial exposure to the apparatus (Dellu et al., 1997; Perrot-Sinal et al., 1996). In fact, recent data support the role of novelty during the first experience in the water maze in explaining the cognitive deficit usually observed in this spatial task with age (Markowska \& Savonenko, 2002). In accord with this, some authors have indicated that the effects of different drugs on performance in the water maze change depending on previous practice in the experimental task (Keith \& Galizio, 1997; Zanotti et al., 1994). Therefore, experience in the task could be a strategy that modifies the effects of pharmacological manipulations. At the end of our experiment, when the mice were 10 months old, no difference in acquisition was observed between groups that received only saline treatment in the three experimental phases $(2,6$, and 10 months of age) and those receiving nicotine in some or all 
phases. If we consider the results obtained during the probe trial, which measure the retrieval of the task, it can be observed that in the re-test phase performed when mice were 10 months old, a deterioration in the retention of the platform position occurred because mice receiving their first training in the task at this age (Groups NotNot-Nic and Not-Not-Sal) did not show any preference for the target quadrant. Data from the probe trial indicate that in groups that had received prior training at 2 months of age and were reevaluated at 10 months of age, a preference for the target quadrant during this re-test phase occurred only in groups receiving saline treatment when trained at 2 months, but not in those treated with nicotine at this age. In addition, groups that had received training in the water maze both at 2 and 6 months of age showed, in general, a clear preference for the training quadrant when reevaluated at 10 months of age. This preference was statistically significant in all groups, with the exception of the Sal-Sal-Nic group, although such animals also spent more time in the target quadrant. These findings indicate that performance during the probe trial is sensitive in detecting the progressive cognitive decline with age.

In summary, the results presented here demonstrate the beneficial effect of early experience, as shown by the evolution of water maze performance at different ages. The current findings also indicate that chronic nicotine treatment does not have a significant effect on the acquisition of the spatial task by naive NMRI mice (at any age tested). However, an interaction between practice in the water maze and nicotine administration cannot be completely discarded because certain differences emerged in the retrieval of the spatial task in expert animals. Further experiments will be needed to explore the effects of a wider number of combinations with different protocols of training in the water maze and administration of nicotinic agonist agents.

\section{ACKNOWLEDGEMENT}

This research was supported by a grant from the Plan Nacional de Investigación Científica, Desarrollo e Innovación Tecnológica (I+D+I) (Spain) (BSO2000-1194).

\section{REFERENCES}

Abdulla FA, Calaminici MR, Stephenson JD, Sinden JD. 1993. Chronic treatments with cholinoceptor drugs influence spatial learning in rats. Psychopharmacology 111: 508-511.

Abdulla FA, Bradbury E, Calaminici MR, Lippiello PM, Wonnacott S, Gray JA, et al. 1996. Relationship between up-regulation of nicotine binding sites in rat brain and delayed cognitive enhancement observed after chronic or acute nicotinic receptor stimulation. Psychopharmacology 124: 323-331.

Adriani W, Macri S, Pacifici R, Laviola G. 2002. Peculiar vulnerability to nicotine oral selfadministration in mice during adolescence. Neuropsychopharmacology 27: 212-224.

Addy NA, Nakijama A, Levin ED. 2003. Nicotinic mechanisms of memory: effects of acute local DH $\beta E$ and MLA infusions in the basolateral amygdala. Cog Brain Res 16: 51-57.

Bannerman DM, Good MA, Butcher SP, Ramsay M, Morris RG. 1995. Distinct components of spatial learning revealed by prior training and NMDA receptor blockade. Nature 378: 182-186.

Barnes CA. 1998. Memory changes during normal aging: neurobiological correlates. In: Martinez JL Jr., Kesrner RP, eds, Neurobiology of Learning and Memory. San Diego, California, USA: Academic Press, 247-287.

Bernal MC, Vicens P, Carrasco MC, Redolat $R$. 1999. Effects of nicotine on spatial learning in C57BL mice. Behav Pharmacol 10: 333-336.

Cain DP. 1998. Testing the NMDA, long-term potentiation, and cholinergic hypotheses of spatial learning. Neurosci Biobehav Rev 22: 181-193.

D'Hooge R, De Deyn PP. 2001. Applications of the Morris water maze in the study of learning and memory. Brain Res Rev 36: 60-90. 
Dellu F, Mayo W, Vallee M, Le Moal M, Simon, H. 1997. Facilitation of cognitive performance in aged rats by past experience depends on the type of information processing involved: a combined cross-sectional and longitudinal study. Neurobiol Learn Mem 67: 121-128.

Erickson C, Barnes CA. 2003. The neurobiology of memory changes in normal aging. Exp Gerontol 38: 61-69.

Faraday M, Elliott BM, Grunberg NE. 2001. Adult vs. adolescent rats differ in biobehavioral responses to chronic nicotine administration. Pharmacol Biochem Behav 70: 475-489.

Faraday M, Elliott BM, Phillips J, Grunberg NE. 2003. Adolescent and adult male rats differ in sensitivity to nicotine's activity effects. Pharmacol Biochem Behav 74: 917-931.

Finch CE. 2003. Neurons, glia and plasticity in normal brain aging. Neurobiol Aging S123-S127.

Fordyce DE, Wehner JM. 1993. Effects of aging on spatial learning and hippocampal protein kinase $\mathrm{C}$ in mice. Neurobiol Aging 14: 309-317.

Foster TC, Gagne J, Massiotte G. 1996. Mechanism of altered synaptic strength due to experience: relation to long-term potentiation. Brain Res 736 : 243-250.

Gallagher M, Bizon J, Hoyt EC, Helm KA, Lund PK. 2003. Effects of aging on the hippocampal formation in a naturally occurring animal model of mild cognitive impairment. Exp Gerontol 38: 71-77.

Hodges H, Sowinski P, Sinden JD, Netto CA, Fletcher A. 1995. The selective 5HT3 receptor antagonist, WAY100289, enhances spatial memory in rats with ibotenate lesions of the forebrain cholinergic projection system. Psychopharmacology 117: 318-332.

Keith JR, Galizio M. 1997. Acquisition in the Morris swim task is impaired by a benzodiacepine but not an NMDA antagonist: a new procedure for distinguishing acquisition and performance effects. Psychobiology 25: 217-228.

Lamberty Y, Gower AJ. 1990. Age-related changes in spontaneous behavior and learning in NMRI mice from maturity to middle age. Physiol Behav 47: 1137-1144.

Lamberty Y, Gower AJ. 1991. Cholinergic modulation of spatial learning in mice in a Morris-Type water maze. Arch Int Pharmacodyn 309: 5-19.

Levin ED. 1996. Nicotinic agonist and antagonist effects on memory. Drug Dev Res 38: 188-195.

Levin ED, Simon BB. 1998. Nicotinic acetylcholine involvement in cognitive function in animals. Psychopharmacology 138: 217-230.

Magnuson KR. 1997. Influence of dietary restriction on ionotropic glutamate receptors during aging in C57BL. Mech Ageing Dev 95: 187-202.

Markowska AL, Savonenko AV. 2002. Protective effect of practice on cognition during aging: Implications for predictive characteristics of performance and efficacy of practice. Neurobiol Lear Mem 78: 294-320.

McGehee DS. 2002. Nicotinic receptors and hippocampal plasticity...it's all in the timing. Trends Neurosci 25: 171-172.

Miyagawa H, Hasegawa M, Fukuta T, Amano M, Yamada K, Nabeshima T. 1998. Dissociation of impairment between spatial memory, and motor function and emotional behavior in aged rats. Behav Brain Res 91: 73-81.

Myhrer T. 2003. Neurotransmitter systems involved in learning and memory in the rat: a meta-analysis based on studies of four behavioral tasks. Brain Res Rev 41: 268-287.

Moffat SD, Zonderman AB, Resnick SM. 2001. Age differences in spatial memory in a virtual environment navigation task. Neurobiol Aging 22: 787-796.

Moragrega I, Carrasco MC, Vicens P, Redolat R. 2003. Spatial learning in male mice with different level of aggressiveness: effects of housing conditions and nicotine administration. Behav Brain Res 147: 1-8.

Morris RGM. 1984. Development of a water-maze procedure for studying spatial learning in the rat. J Neurosci Meth 11: 47-60.

Moser MB, Trommald M, Egeland T, Andersen P. 1997. Spatial training in a complex environment and isolation alter the spine distribution differently in rat CA1 pyramidal cells. J Comp Neurol 380: 373-381.

Perrot-Sinal TS, Kostenuik MA, Ossenkopp KP, Kavaliers M. 1996. Sex differences in performance in the Morris water maze and the effects of initial nonstationary hidden platform training. Behav Neurosci 110: 1309-1320.

Pitsikas N, Biagini L, Algeri S. 1991. Previous experience facilitates preservation of spatial memory in the senescent rat. Physiol Behav 49: 823-825.

Riekkinen M, Aroviita L, Kivipelto M, Taskila K, 
Riekkinen P Jr. 1996. Depletion of serotonine, dopamine and noradrenaline in aged rats decreases the therapeutic effect of nicotine, but not of tetra-handdroaminoacridine. Eur J Pharmacol 308: 243-250.

Riekkinen M, Riekkinen P Jr. 1997. Nicotine and Dcycloserine enhance acquisition of water maze spatial navigation in aged rats. Neuroreport 8: 699-703.

Sarter M, Bruno JP. 1998. Age-related changes in rodent cortical acetylcholine and cognition: Main effects of age versus age as an intervening variable. Brain Res Rev 27: 143-156.

Saucier D, Cain DP. 1995. Spatial learning without NMDA receptor-dependent long-term potentiation. Nature 378: 186-189.

Socci D, Crandall B, Arendash G. 1995. Chronic antioxidant treatment improves the cognitive performance of aged rats. Brain Res 693: 88-94.

Tanila H, Shapiro M, Gallagher M, Eichenbaum H. 1997. Brain Aging: changes in the nature of information coding by the hippocampus. $\mathrm{J}$ Neurosci 17: 5155-5166.
Van Praag H, Kempermann G, Gage FH. 2000. Neural consequences of environmental enrichment. Nature Rev 1: 191-198.

Vicens P, Bernal MC, Carrasco MC, Redolat R. 1999. Previous training in the water maze: differential effects in NMRI and C57BL mice. Physiol Behav 67: 197-203.

Vicens P, Carrasco MC, Redolat R. 2002. Effects of early spatial training on water maze performance: a longitudinal study in mice. Exp Gerontol 37 : 575-581.

Whishaw IQ. 1989. Dissociating performance and learning deficits on spatial navigation tasks in rats subjected to cholinergic muscarinic blockade. Brain Res Bull 23: 347-358.

Wilson IA, Ikonen S, McMahan RW, Gallagher M, Eichenbaum H, Tanila H. 2003. Place cell rigidity correlates with impaired spatial learning in aged rats. Neurobiol Aging 24: 297-305.

Zanotti A, Arban R, Perazzolo M, Giusti P. 1994. Diazepam impairs place learning in naive but not in maze-experienced rats in the Morris water maze. Psychopharmacology 115: 73-78. 

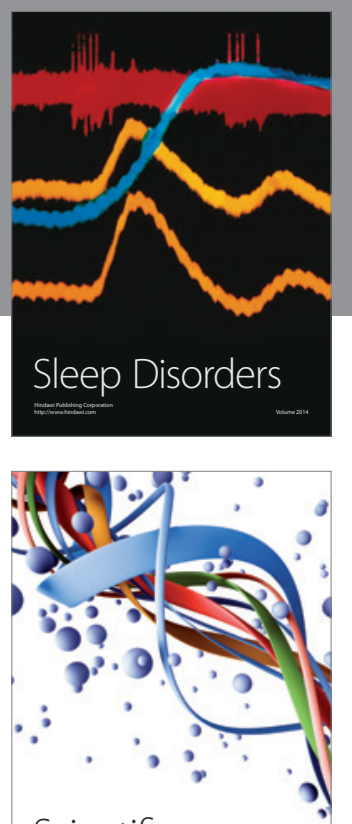

Scientifica
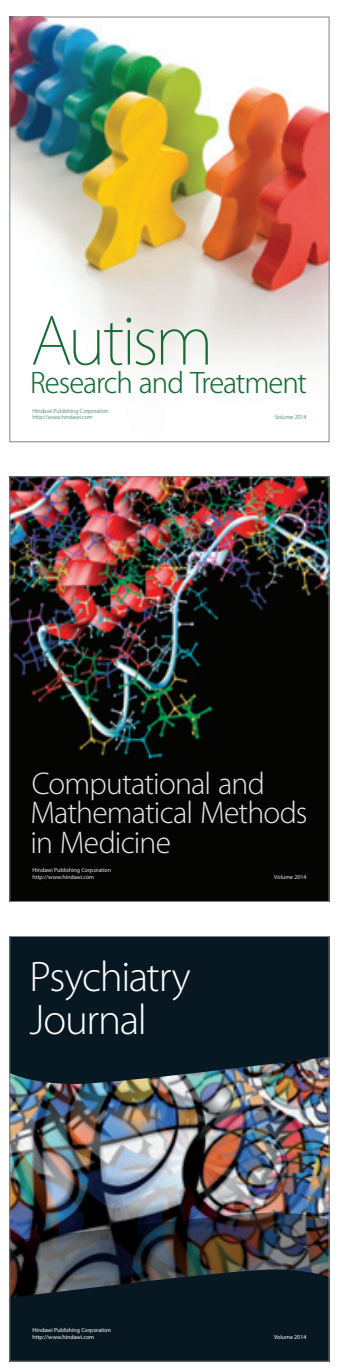
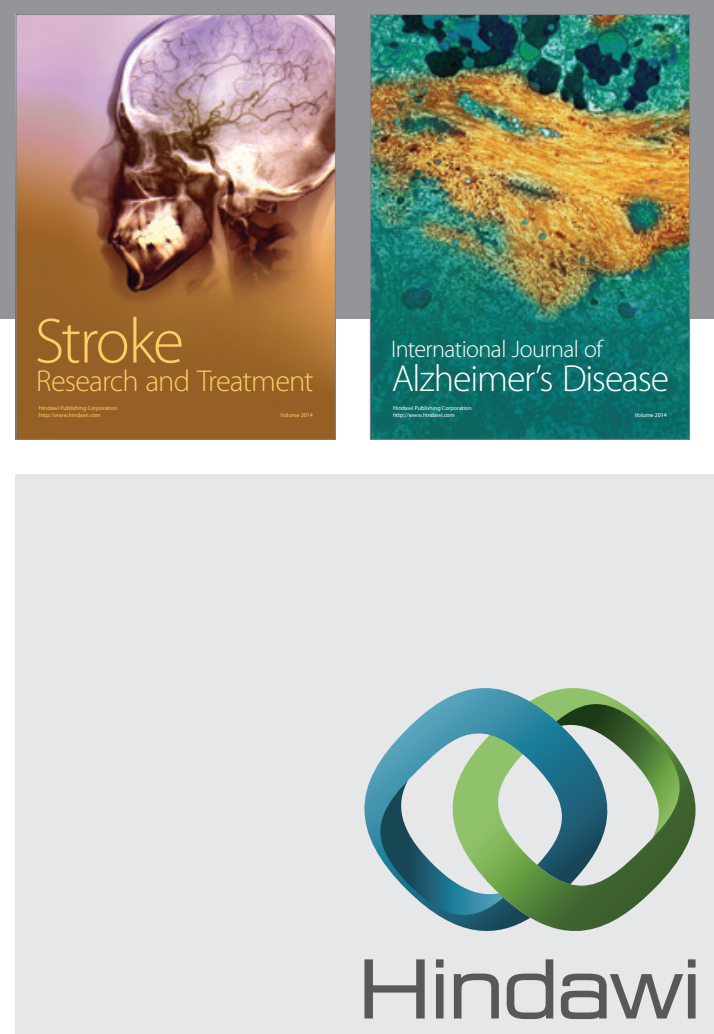

Submit your manuscripts at

http://www.hindawi.com
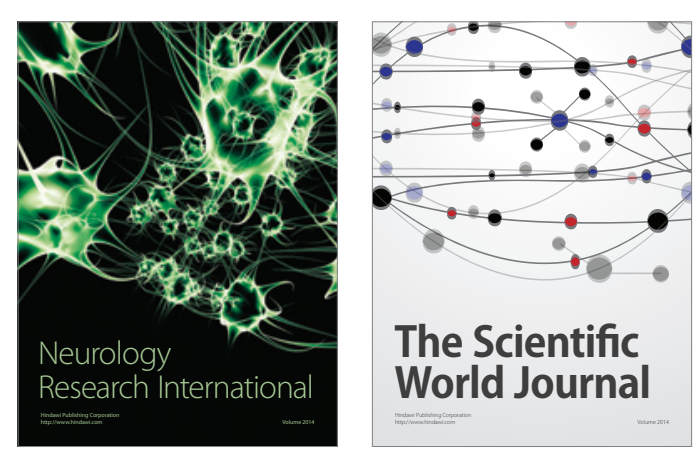

The Scientific World Journal

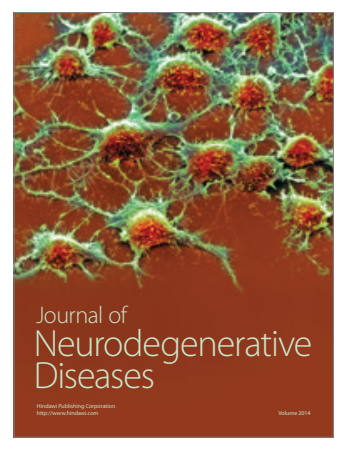

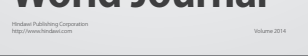

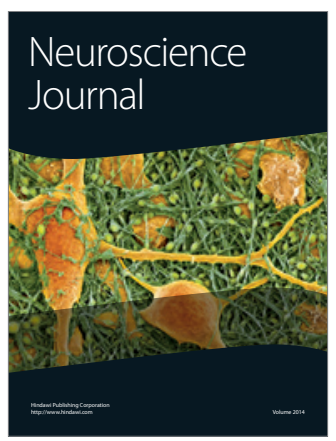

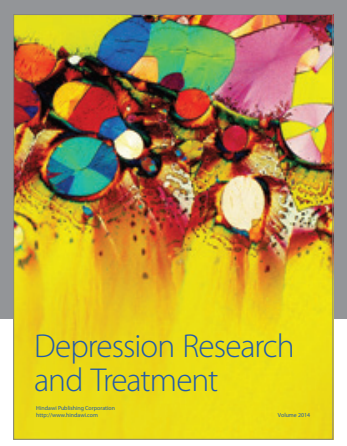
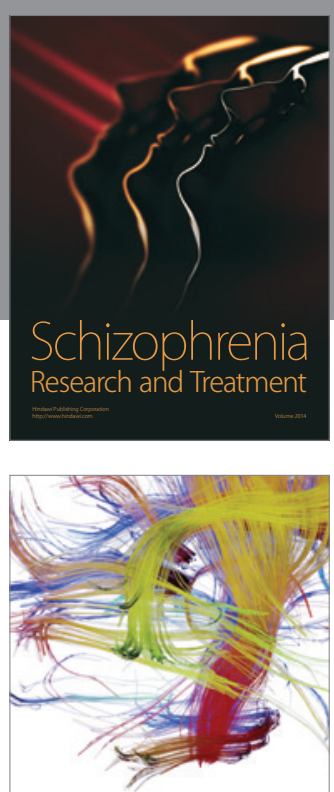

Brain Science

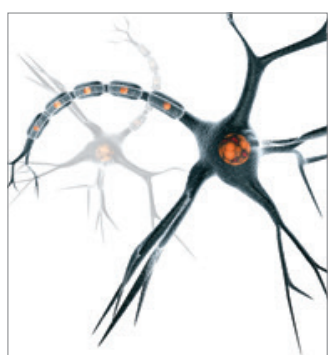

Neural Plasticity
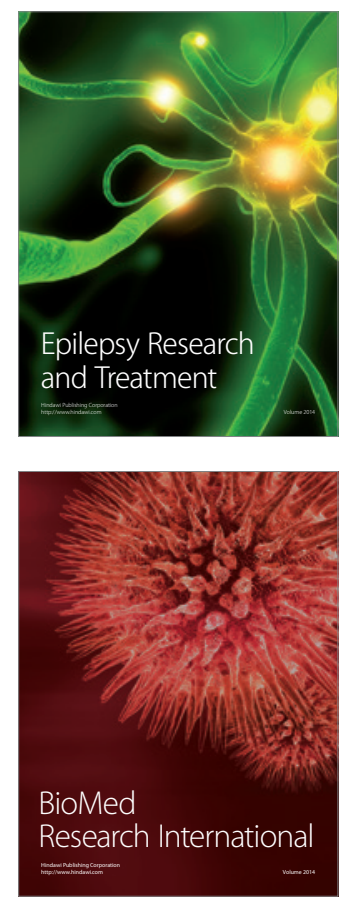

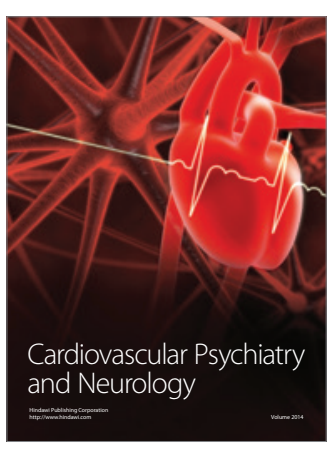

Parkinson's

Disease
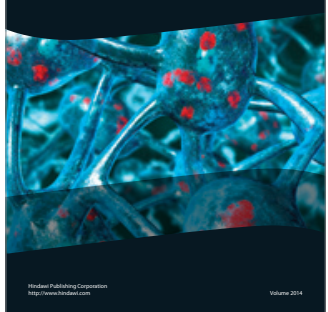